\title{
SOBRE LA EVOLUCIÓN \\ DE LA ARGUMENTACIÓN EN LA \\ DOGMÁTICA PRIVADA FINLANDESA \\ EN EL PERÍODO 1920-1960
}

\section{Introducción}

1.1.

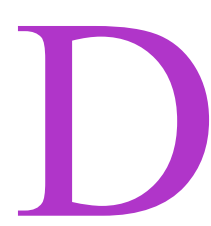

e acuerdo con una idea bastante común la investigación en la dogmática jurídica está estrechamente conectada con el derecho positivo, sus resultados tienden a ser más reproductivos que productivos y sus lazos con el derecho legislado la hacen ser en gran medida inmune a las tendencias intelectuales. Esta concepción es, si no equivocada, sí al menos indudablemente parcial.

Puede objetarse que la investigación en la dogmática jurídica está considerablemente menos asociada al derecho positivo de lo que generalmente se cree. Esto ocurre especialmente en la dogmática privada. Al buscar problemas desafiantes y difíciles los estudiosos tienen grandes probabilidades de seleccionar su tema de un campo en el que el derecho escrito es de poca importancia.

Un argumento incluso más poderoso en contra de esta concepción es el hecho de que el Derecho positivo no ofrece a los investigadores las premisas ontológicas, epistemológicas y metodológicas en las que la dogmática jurídica necesariamente se basa ${ }^{1}$. Esto implica que la dogmática jurídica puede desarrollarse autónomamente, con independencia de los cambios a los que el Derecho positivo está sometido y con independencia de que los resultados de la investigación que presenta como derecho válido pueden cambiar significativamente mientras el derecho escrito permanece inalterado.

En este ensayo voy a analizar la evolución de la argumentación en la investigación sobre Derecho privado finlandés en el

${ }^{1}$ Por estas premisas quiero decir respuestas a las preguntas, «¿qué es el Derecho?», «¿qué es el conocimiento del Derecho en el Derecho?» y «¿qué métodos deben utilizarse para obtener conocimiento acerca del Derecho?» 
período 1920-1960. También voy a intentar establecer cómo influyeron los cambios en cuestión en la naturaleza de los resultados producidos por la dogmática jurídica, y en las posiciones tomadas sobre el contenido de las normas legales (proposiciones interpretativas) $)^{2}$.

1.2. Al comienzo de este siglo el estudio doctrinal del Derecho en Finlandia estaba muy abierto a la influencia extranjera. Tenía escasa tradición propia y los vacíos eran cubiertos por medio de ejemplos de otros países. Los estímulos procedían principalmente de dos direcciones: Alemania y Escandinavia, en particular Suecia. En un principio estas dos corrientes se reforzaban mutuamente debido a la influencia alemana sobre la investigación de derecho privado en Suecia ${ }^{3}$. Esta situación cambió pronto. En Suecia empezaba a manifestarse una nueva tendencia muy crítica con la llamada dogmática conceptualista (Begriffs jurisprudenz). Esta línea de pensamiento sería finalmente conocida en el mundo como Realismo Jurídico Escandinavo.

Como consecuencia de este desarrollo los investigadores de Derecho privado finlandeses tenían a su disposición en los años veinte dos modelos muy diferentes de investigación. Uno estaba fundado en la tradición de la dogmática conceptualista, que había sido importada a partir de 1880. Los estudios representativos de este enfoque formaban la estructura de la dogmática privada finlandesa. El otro modelo de investigación estaba en relación con la nueva escuela de pensamiento que acababa de nacer en Escandinavia.

Las diferencias entre los dos marcos de referencia eran muy grandes. La dogmática conceptualista consideraba el sistema jurídico una entidad sistemática basada en dos categorías fundamentales: las instituciones jurídicas (por ejemplo la compraventa, el arrendamiento o la garantía) y los derechos subjetivos (por ejemplo la propiedad o un derecho de crédito). El ordenamiento era considerado un sistema de instituciones jurídicas y de derechos subjetivos.

${ }^{2}$ El artículo está basado en mi libro Lainoppi ja metafysiikka. Tutkimus skandinaavisen oikeusrealismin tieteenkuvasta ja sen vaikutuksesta Suomen siviilioikeuden tutkimuksessa vuosina 1920-1960 (1988) (Dogmática jurídica y metafísica. Un estudio sobre el enfoque científico del Realismo Jurídico Escandinavo y su influencia sobre la investigación finlandesa de Derecho civil en el periodo 1920-1960.)

${ }^{3}$ Véase Jan-Olof Sundell, Tysk påverkan på svesk civilrättsdoktrin 1870-1914 (1987), passim. 
De acuerdo con ese modelo la labor de la ciencia jurídica era estudiar la naturaleza y las interrelaciones de las categorías y elaborar teorías generales que atribuyeran consecuencias jurídicas a estas categorías. Las teorías podían usarse para encontrar soluciones a problemas jurídicos concretos asignando el caso problemático en cuestión a la categoría adecuada, tras lo cual la consecuencia jurídica podía determinarse por medio de la doctrina general conectada a esta categoría ${ }^{4}$.

Si intentamos caracterizar en un nivel mayor de abstracción la investigación basada en el enfoque conceptualista, podemos decir que concibe la ciencia jurídica como una ciencia racional y dogmática fundada en principios. Hay una estrecha relación entre la dogmática y la tradición cultural jurídica, en la que los principios juegan un importante papel. Las reglas jurídicas concretas son aplicaciones deductivas particulares de principios establecidos por la doctrina general.

El método usado por el investigador para fijar el contenido de una regla jurídica concreta consiste en elucidar una antigua y sofisticada tradición. La habilidad requerida para resolver problemas concretos se basa en un buen dominio de todo el sistema. Solamente el ordenamiento jurídico como un todo proporciona los principios a la luz de los cuales el caso debe ser examinado, así como el marco de referencia de la crítica jurídica dirigida contra las decisiones judiciales.

El enfoque del Realismo Escandinavo era enteramente diferente. Afirmaba que el sistema jurídico no es un sistema lógico, sino un fenómeno empírico. De esta forma, el método deductivo favorecido por la dogmática jurídica conceptualista no es un medio adecuado de estudiar el derecho. Este punto de vista era firmemente sostenido por las teorías filosóficas de Axel Hägerström.

Hägerström mantenía que las categorías jurídicas básicas, como los conceptos «derecho (subjetivo)» y «deber», eran parte de la metafísica práctica con la que la ciencia jurídica estaba de numerosas formas interconectada. Él creía que podía probar que estos conceptos eran meras cáscaras vacías, palabras carentes de cualquier connotación o denotación ${ }^{5}$. Esto significaba que un argumento que pretendiera justificar una solución por

${ }^{4}$ De los artículos escandinavos que presentan el método de la dogmática conceptual, debe hacerse especial referencia a Francis Hagerup, «Nogle Ord on den nyere Retsvidenskabs Karakter», $T f R, 1888$, págs. 1-58.

${ }^{5}$ Véase eg Axel Hägerström, Inquiries into the nature of law and morals (1953), págs. 1-16. 
medio de la referencia a una categoría jurídica no podía ser en realidad defendido, ya que es imposible fundar nada en elementos no existentes.

De acuerdo con el Realismo Jurídico Escandinavo, el sistema jurídico consta de normas jurídicas que son consideradas relaciones entre hechos y consecuencias jurídicos. La regulación jurídica es una forma de ingeniería social ${ }^{6}$. Asociando efectos jurídicos a grupos de circunstancias convenientemente seleccionados es posible cambiar de una manera adecuada el comportamiento de la gente y desarrollar la sociedad de acuerdo con un diseño calculado. La dogmática debe tener en cuenta la función de las normas jurídicas como instrumentos de ingeniería social.

Cuando la dogmática jurídica se utiliza para resolver un caso donde hay una laguna o algún punto ambiguo en el derecho positivo, la solución debe basarse en el hecho de que sus efectos cumplan el objetivo social pretendido. En otras palabras, las llamadas consideraciones prácticas deben ser enfatizadas en la argumentación jurídica mucho más que antes. El papel asignado a estos argumentos era el mismo que el que el modelo conceptualista asignaba a las doctrinas generales.

En el Realismo Escandinavo se le daba también más importancia a la práctica jurídica y a los precedentes jurisprudenciales. De acuerdo con la nueva escuela de pensamiento, la validez de una norma jurídica significa su eficacia entre las autoridades. De esta forma, un jurista que pretende que los resultados de su investigación correspondan al derecho válido no puede omitir la práctica jurídica. Esta visión también entraba en agudo conflicto con la concepción subyacente en la dogmática conceptualista. En efecto, ésta afirmaba que la solución a un problema jurídico debe ser derivada del sistema jurídico. Desde esta perspectiva era completamente erróneo intentar resolver una cuestión estudiando las decisiones judiciales, ya que éstas son tomadas por juristas que aun estando suficientemente versados en práctica jurídica, no tiene el conocimiento profundo de las sofisticaciones del sistema.

${ }^{6}$ La idea de la ingeniería social planteada por el Realismo Escandinavo puede encontrarse claramente en, por ejemplo, el método de Lundstedt de bienestar social, el método de interpretación teleológica de Ekelöf y en el enfoque de Alf Ross sobre la política (policy) jurídica. Véase eg Lundstedt, Superstition or rationality in action for peace (1925), pág. 129 y sig.; Ekelöf, Teleological construction of statutes, Sc. St. L., 1958, págs. 75 y sig., y Ross, Om ret og retfaerdighed (1953), págs. 417 y sig. 
Después de este breve esbozo de los dos modelos que han tenido un considerable impacto en la investigación de Derecho privado en Finlandia, voy a intentar elucidar cómo se manifestó la tensión entre ambos en la argumentación jurídica y los resultados obtenidos. El período a examinar cubre los años 1920-1960.

Debe tenerse en cuenta que en los años veinte el enfoque conceptualista había asumido ya su forma definitiva, mientras que las ideas del Realismo Escandinavo estaban sólo en el principio de su desarrollo ${ }^{7}$. Consecuentemente, la tensión entre las dos teorías no se había manifestado todavía con claridad. Sin embargo, parece apropiado comenzar en esa década, pues esto puede permitirnos estudiar el proceso de cambio desde el principio.

\section{La argumentación en la dogmática jurídica}

en los primeros años veinte

En los años veinte el auge de la dogmática conceptualista había ya pasado en Alemania. Había sido severamente criticado por los seguidores de la Escuela del Derecho Libre («Freirechtsschule») y de la llamada jurisprudencia de intereses («Interessen jurisprudenz») por enfatizar la estructura sistemática del ordenamiento a costa de otros aspectos. De acuerdo con estos críticos, era impensable que la vida pudiera ser reducida a modelos determinados por conceptos y que el mundo pudiera ser dominado por medio de conceptos y definiciones.

Los juristas finlandeses conocían la crítica dirigida contra el marco de referencia conceptualista y ésta había recibido incluso alguna acogida favorable en escritos relacionados con la metodología de la dogmática jurídica. El enfoque conceptualista era sin duda rechazado en la medida en que pretendía derivar consecuencias jurídicas del sistema de conceptos jurídicos sin tomar en consideración si estos resultados cumplían ciertas necesidades sociales, económicas o morales. Sin embargo, los méritos de la dogmática en cuanto a claridad sistemática y seguridad jurídica

${ }^{7}$ Los realistas escandinavos tenían diferentes opiniones sobre la relación entre sus teorías y la cultura jurídica escandinava tradicional. Lundstedt consideraba su acercamiento una innovación revolucionaria, mientras que Ross pensaba que su propia teoría retomaba la vieja tradición danesa, originada en Orstedt pero interrumpida durante el período de dominación de la dogmática conceptualista. 
eran acentuados. Estas ventajas se consideraban tan importantes que parecía imposible abandonar el método conceptualista.

Kivimäki, una figura prominente en la investigación de Derecho privado finlandesa ${ }^{8}$, afirmaba que «la dogmática jurídica es y debe ser principalmente conceptual». Una crítica bien fundada contra el método de la dogmática podía realizarse sometiendo los resultados obtenidos por este método a un examen basado en los criterios desarrollados por la «Freirechtsschule» y por la jurisprudencia de intereses.

En cuanto a la propia dogmática, sus características correspondían en gran medida a los puntos de vista adoptados en los escritos metodológicos. El acercamiento que prevalecía en la ciencia jurídica era fundamentalmente conceptualista. Entre los problemas planteados había una considerable cantidad de cuestiones relativas a categorización.

La determinación de a qué categoría jurídica pertenecía un fenómeno problemático era considerada un problema científico real. Cuando el fenómeno había sido clasificado, sus consecuencias jurídicas se establecían derivándolas de los principios jurídicos peculiares de esa categoría. Sin embargo, el análisis no siempre se extendía a los efectos jurídicos. En realidad se pensaba que en muchos casos la mera categorización era un resultado suficiente, pues esto ya permitiría al lector informado inferir él mismo las consecuencias jurídicas.

La investigación de Derecho privado finlandesa difería, por ejemplo, de la dogmática conceptualista representada por Puchta en que no consideraba las construcciones jurídicas entidades a priori más allá de la esfera de influencia del legislador. Por el contrario, se mantenía que las categorías debían derivarse del Derecho positivo ${ }^{9}$. Este requisito no era, sin embargo, en la mayoría de los casos más que papel mojado. En realidad, las categorías eran extraídas de los resultados obtenidos en los estudios alemanes de Derecho privado, mientras que las disposiciones casuísticas del Derecho positivo proporcionaban sólo un pequeño apoyo.

Sin embargo, la dogmática finlandesa mostraba respeto por el Derecho positivo en el sentido de que no aceptaba esa clase de

${ }^{8}$ T. M. Kivimäki fue profesor de Derecho civil en la Universidad de Helsinki durante 1931-1956. Hasta el final de la segunda guerra mundial desempeñó importantes cargos públicos y fue primer ministro de Finlandia durante 1932-1937.

${ }^{9}$ Inter alia Caselius, Panttioikeuden käsitteestä Suomen oikeuden mukaan (1925). (El concepto del derecho de gravamen en el Derecho finlandés.) 
deducciones basada en el enfoque conceptualista que conducía claramente a soluciones incompatibles con el Derecho positivo. Si el resultado deducido del sistema y la norma jurídica chocaban, esta última debía prevalecer. Esto limitaba el uso del método conceptualista a los problemas que no podían resolverse aplicando el Derecho positivo.

En la práctica, esta restricción no era, sin embargo, muy significativa porque había en la legislación civil numerosas lagunas, algunas de las cuales atañían a cuestiones importantes. Como Kivimäki señaló, habría sido engañoso afirmar que las principales normas del Derecho privado se fundaban o podían fundarse en el Derecho escrito, «que ni siquiera mencionaba el fenómeno jurídico más común y significativo en el comercio, y el contrato entre ausentes» ${ }^{10}$.

Naturalmente, las lagunas en el Derecho positivo pueden integrarse por otros medios distintos del recurso a la doctrina conceptualista. Como se ha explicado más arriba, el Realismo Escandinavo destacaba la importancia de los argumentos prácticos sustanciales y de los casos judiciales. Pero estas ideas no recibieron apoyo en Finlandia en los primeros años veinte.

En las tesis doctorales y en otros tratados académicos había generalmente muy pocas referencias a la práctica jurídica ${ }^{11}$. Normalmente los precedentes eran citados sólo como ilustraciones; en muy pocas ocasiones eran usados, como argumentos para sustanciar una proposición interpretativa, y lo más común era que fueran objeto de crítica.

El recurso a consideraciones prácticas era también muy inusual. Desde el punto de vista de la metodología de la dogmática jurídica no era aconsejable justificar soluciones señalando que sus cualidades instrumentales servían ciertos objetivos. Naturalmente, los estudiosos de ese tiempo no desconocían los aspectos instrumentales, pero debían defender sus resultados de otra forma, preferiblemente derivándolos del sistema de Derecho privado.

Este punto puede ser demostrado por medio de un ejemplo tomado del derecho de responsabilidad civil. De acuerdo con la doctrina general en este campo del Derecho, la responsabilidad por daños requería negligencia de la parte causante, la responsabilidad sin negligencia sólo podía establecerse específicamente

${ }^{10}$ Kivimäki, Uusia virtauksia siviililainopin alalla (Tendencias en la dogmática civil), Defensor Legis, 1921, pág. 376.

${ }^{11}$ Hubo también excepciones, como Haataja, Vuokran käsite (1921) (El concepto de arrendamiento), y Caselius, Omistajan kiinnityksestä Suomen oikeuden mukaan (1924) (Sobre la hipoteca en el Derecho finlandés). 
basándose en la legislación o en un contrato. Consecuentemente, la investigación que llegara a la conclusión de que había responsabilidad por daños sin negligencia debía ser justificada indicando las bases específicas en cuestión.

Era difícil, sin embargo, encontrar tales bases en todos los casos en que principios de política legislativa exigirían responsabilidad sin negligencia. El problema se resolvía adoptando la noción de declaración tácita de voluntad, que permitía basar la responsabilidad sin negligencia, por ejemplo, en una garantía tácita dada por la parte causante obligándola a una responsabilidad estricta ${ }^{12}$. Es obvio que esta argumentación se basaba en una pura ficción y que el concepto «declaración tácita de voluntad» contenía una contradicción inherente, pero de esta forma la estructura de la justificación permanecía aceptable y podía evitarse el uso abierto de consideraciones prácticas.

Sin embargo, sería incorrecto decir que los argumentos usados en la dogmática estaban completamente vacíos de consideraciones prácticas. Los juristas, con frecuencia, están pragmáticamente orientados y consideran la posibilidad de uso de los resultados más importante que la consistencia metodológica. Si una solución se torna poco práctica y no hay un medio metodológicamente permisible de eliminar este defecto, el método es disimuladamente adaptado a la situación. De esta forma podían encontrarse consideraciones prácticas y a veces éstas eran utilizadas incluso para rectificar conclusiones alcanzadas por medio del método conceptualista ${ }^{13}$.

Es, sin embargo, claro que la posición oficialmente débil de las consideraciones prácticas retrasó su elucidación e impidió una reflexión abierta y sistemática sobre medios y fines. Los argumentos utilizados eran bastante laxos y en muchos casos no habrían cumplido las condiciones fijadas por el Realismo Escandinavo ${ }^{14}$. Lundstedt y Ross, en particular, trazaron una distinción tajante entre argumentos prácticos y de equidad. Sostenían que los primeros estaban basados en el conocimiento de los efectos sociales de las normas jurídicas y de las decisiones judiciales, mientras que había un factor parcialmente irracional subyacente

${ }^{12}$ Véase eg Kivimäki, Asianajajan siviilioikeudellinen vastuu (1924) (La responsabilidad civil del abogado), pág. 200.

${ }^{13}$ Así, eg Caselius, op. cit., págs. 223-224.

${ }^{14}$ Por ejemplo, un jurista podía referirse a los legítimos intereses de una parte en una relación jurídica sin justificar por qué precisamente esos intereses debían protegerse en ese caso. 
en los segundos, i.e. el sentido de justicia ${ }^{15}$. Los argumentos abiertamente utilizados en la dogmática finlandesa eran formulados de tal forma que la mayoría de ellos habría sido clasificada en la categoría de argumentos de equidad, rechazados por el Realismo Escandinavo.

\section{El Episodio Realista al final de los años veinte}

La situación que acabo de describir cambió al final de los años veinte, cuando las principales ideas de Hägerström y Lundstedt se hicieron familiares entre los iusprivatistas finlandeses. Uno de sus principales seguidores fue Sainio ${ }^{16}$.

Sainio intentó hacer uso de estas teorías en su tesis doctoral sobre las inmisiones en el Derecho finlandés. Él repudiaba el método conceptualista, «deducción de conceptos». En su opinión, el ordenamiento no era un sistema de construcciones jurídicas y de principios conectados con ellas, sino que consistía en un conjunto de normas efectivamente observadas por las autoridades.

En este sentido Sainio era de la misma opinión que Lundstedt. Tal posición no era, sin embargo, un marco de referencia muy adecuado para la investigación en dogmática jurídica. Tradicionalmente, esta investigación no trata de las regularidades típicas del comportamiento social, sino de las normas que regulan este comportamiento.

Sainio era, en este sentido, un representante de la dogmática tradicional. Sus afirmaciones programáticas acentuando el realismo y el empirismo no coincidían completamente con las ideas expresadas en sus investigaciones concretas. En realidad, él pasó por ciertas fases en su pensamiento tras las cuales abandonó su punto de partida puramente empirista. Para él, «derecho efectivo», finalmente, significaba lo mismo que «derecho viviente», una noción opuesta a los polvorientos principios jurídicos del enfoque conceptualista que no servían adecuadamente a la sociedad moderna. El derecho viviente había de encontrarse en el Derecho positivo interpretándolo de una forma nueva, sin observarlo a través de las lentes ofrecidas por el marco de referencia conceptualista.

${ }^{15}$ Así, inter alia Lundstedt, Legal thinking revised (1956), págs. 53 y sig., y Ross, Om ret og retfaerdighed (1953), págs. 461 y sig.

${ }^{16}$ Viljo Sainio, Eräitä oikeuden olemusta käsitteleviä teorioja (Algunas teorías sobre la esencia del Derecho), Defensor Legis 1928, págs. 93 y sig. 
De esta forma, el programa de investigación de Sainio tenía en realidad algo en común con el positivismo jurídico. El principal argumento del positivismo en contra de la dogmática conceptualista era que ésta constituía un sistema extranjero no basado en el Derecho privado finlandés. Por tanto, este método no era digno de confianza. Si una solución era derivada del sistema conceptualista, no había ninguna garantía de que estuviera de acuerdo con el espíritu del Derecho positivo. El principal argumento de la llamada Escuela de Uppsala, según el cual las construcciones conceptualistas eran metafísicas y no captaban ningún fenómeno que perteneciera al reino de la realidad, terminó siendo secundario ${ }^{17}$.

A pesar del énfasis que puso en el positivismo jurídico, Sainio era naturalmente conocedor del hecho de que había muchas lagunas en el Derecho positivo. Él sostenía que en estos casos uno debe examinar el objetivo de la regulación legal. Cuando una cuestión no está prevista por el Derecho el jurista debe, utilizando consideraciones prácticas, tratar de desarrollar normas que sean apropiadas desde el punto de vista de la ingeniería social.

Las ideas que acabo de presentar empezaron a tener efecto al final de los años veinte. La importancia de las consideraciones prácticas cambió considerablemente. El cambio afectó tanto al número de estos argumentos como, en cierta medida, a su naturaleza. Los argumentos abiertos y sustanciales utilizados antes eran en su mayoría lo que Summers ha llamado razones de corrección (Rightness Reasons) ${ }^{18}$. Brevemente, estas razones eran argumentos que buscaban un tratamiento equitativo de las partes de una relación jurídica y que obtenían su capacidad de justificación de su conformidad con una concepción de justicia. Como tales, eran ejemplos del «método de justicia» condenado severamente por Lundstedt en particular.

Sainio y algunos otros juristas, como por ejemplo Kauppi, utilizaron, por el contrario, además, razones sobre objetivos como argumentos; en otras palabras, justificaban sus proposiciones

17 Sainio parecía aprobar la idea en sí misma. Véase Viljo Sainio, Elinkeinon harjoittamisesta johtuvat suhteet naapureihin Suomen yksityisoikeuden mukaan (1929) (Sobre las relaciones vecinales en el desarrollo de una industria en el Derecho finlandés), págs. 21 y sigs.

${ }^{18}$ Véase en este punto Robert S. Summers, «Two types of reasons of substance in common law cases», ARSP Beiheft, núm. 11 (1979), págs. 218 y sigs. La distinción también es brevemente explicada por Aulis Aarnio, The rational as reasonable (1986), pág. 94. 
interpretativas señalando que la adopción de tal criterio posibilitaría la consecución de ciertos objetivos sociales. Estos objetivos estaban normalmente conectados con la vida del comercio y con la industrialización ${ }^{19}$. El mismo tipo de argumentación aparecía en algunos artículos de menor importancia.

El método escandinavo que destacaba las consideraciones prácticas alcanzó su primer punto culminante en 1931 con la publicación de la tesis doctoral de Af Hällström ${ }^{20}$, que trataba del significado del llamado error en la declaración de voluntad en el Derecho de obligaciones. Su método de investigación presentaba claramente las siguientes características típicas del Realismo Escandinavo: 1) la noción del ordenamiento como un instrumento de ingeniería social $\mathrm{y}$, consecuentemente, 2) la idea de que los efectos jurídicos deben conectarse con hechos y circunstancias concretas en lugar de con construcciones conceptualistas; 3) la opinión de que la salvaguarda de intereses sociales comunes es más importante que la protección de intereses individuales y que el cumplimiento de requisitos de equidad, y 4) el principio de que en la argumentación no está permitido el recurso a la ficción.

Partiendo de estas premisas, Af Hällström llegó a la conclusión de que en el Derecho de obligaciones el interés del intercambio debía prevalecer. Sólo debía tomarse en consideración el error de una de las partes al expresar su voluntad si no entraba en conflicto con el interés del intercambio. Este objetivo podía conseguirse elaborando normas que protegieran la razonable confianza que el comportamiento (verbal) de la otra parte producía en quien no sufría el error (la llamada teoría de la confianza). El principal objetivo de este estudio era establecer la relevancia del error en la declaración de voluntad, cuando las normas jurídicas en cuestión tenían una formulación basada en tal teoría.

${ }^{19}$ En la argumentación de Sainio, uno puede detectar una especie de admiración por las máquinas y por la eficiencia funcional (expresiones de la misma actitud pueden encontrarse en el arte y literatura de la época). Sainio escribió: «Si alguien construye, por ejemplo, una cabaña o planta un jardín cerca de unos rápidos con energía hidráulica potencial, debe estar preparado para soportar la explotación de la energía y la instalación de fábricas en la zona.» En su opinión, en tales circunstancias ni siquiera una molestia excesiva causada por la inmisión es ilícita, pues no puede ser considerada como inesperada.

${ }^{20}$ Erik af Hällström, Om villfarelse sasom divergens mellan vilja och förklaring vid rättshandlingar pa förmögenhetsrättens omrade (1931). 


\section{Regreso a la dogmática jurídica conceptualista}

4.1. La investigación de Derecho privado basada en los métodos escandinavos no duró. El enfoque utilizado en la mayoría de los estudios académicos realizados en los años treinta era claramente conceptualista. Los juristas que habían introducido la nueva técnica de argumentación en Finlandia no publicaron ninguna obra importante antes de la segunda guerra mundial.

Es difícil definir las causas de este cambio. Quizás tenga relación con el creciente conservadurismo de aquel tiempo. También es posible que el aumento del poder político de Alemania produjera un resurgir de su influencia cultural e hiciera que los investigadores volvieran la cabeza a Alemania y su vieja cultura ${ }^{21}$. La doctrina escandinava encontró una fuerte oposición en Caselius, quien, en respuesta al estudio de Sainio, criticó con dureza en varios artículos a la «Escuela de Hägerström-Lundstedt» ${ }^{22}$. Los artículos de Caselius parece que produjeron algún efecto ${ }^{23}$.

Al investigar las razones del cambio uno debe tener en cuenta que el simple azar pudo haber jugado un importante papel. En aquel tiempo la comunidad de juristas en Finlandia era muy pequeña. En los años treinta el producto de la investigación en Derecho privado consistía principalmente en los escritos de unos diez juristas. En estas condiciones, un pequeño número de estudiosos productivos podía influir en el campo entero. Los representantes más consistentes de la dogmática conceptualista, Hakulinen y Heikonen, eran escritores prolíficos ${ }^{24}$.

${ }^{21}$ Es cierto que no hubo tal tendencia en la cultura popular (en música, cine y literatura). Véase en este punto Olli Jalonen, Kansa kultuurin virroissa (1985) (La gente en medio de las corrientes culturales), págs. 108 y sigs.

${ }^{22}$ Ilmari Caselius, «Den Hägerström-Lundstedtska skolan i Finland», FJFT, 1929, págs. 177 y sigs. Véase también el memorándum que Caselius escribió como oponente oficial de la tesis doctoral de Sainio, Lakimies, 1929, págs. 329 y sigs. Caselius fue profesor de Derecho civil en la Universidad de Helsinki entre 1936-1956.

${ }^{23}$ Probablemente el rechazo por Af Hällström de las ideas de Lundstedt en su «Lectio praecursoria» («Lección introductoria») dada durante el debate público sobre su tesis doctoral fue una reacción a estos artículos. Realmente, no había grandes diferencias entre los enfoques de Af Hällström y Lundstedt sobre la metodología de la dogmática. Véase Af Hällström, «Nagot on jurisdiska begrepp, deras uppgift och berättigande», FJFT, 1931, págs. 355 y sigs.

${ }^{24}$ Hakulinen cubrió en su investigación un gran número de ramas del Derecho civil. Fue miembro del Tribunal Supremo en 1937-1952 y presidente de la Corte de Apelaciones de Helsinki en 1952-1971. Heikonen empezó su carrera como investigador en el campo del Derecho de sucesiones y pasó después a 
Si examinanos el método que prevalecía en los estudios de Derecho civil de aquel tiempo, podemos ver que los problemas de categorización habían recobrado una posición importante. Esto se observa con la mayor claridad en el libro de Heikonen sobre la comunidad hereditaria. Realmente, este estudio no ofrece ninguna solución a problemas prácticos, sino que trata de cuestiones tales como «¿Es la comunidad hereditaria una persona jurídica?», «¿Es la comunidad hereditaria una comunidad de bienes?» y «¿Es la comunidad hereditaria un objeto?»

El libro tuvo, en general, una acogida favorable, lo que refleja que el enfoque de categorías era una posición establecida en la comunidad científica ${ }^{25}$. Este libro se consideró de gran importancia práctica, aunque no ofrecía directamente soluciones a problemas prácticos ${ }^{26}$. Se pensaba que era imposible resolver casos prácticos sin elucidar primero la naturaleza y esencia de la comunidad hereditaria. La concepción de las categorías era un medio correcto para encontrar y justificar la norma relevante.

Como dije más arriba, los partidarios de la dogmática conceptualista reconocían la prevalencia del Derecho escrito sobre la doctrina. Esta actitud parecía implicar el requisito metodológico de que la categorización debía ser contrastada con el Derecho escrito. En otras palabras, las categorías debían ser hipótesis que eran refutadas cuando contradecían el Derecho positivo y confirmadas cuando se probaba que «predecían» correctamente el contenido de la norma.

Cuando examiné en qué medida se realizaban tales comprobaciones de facto, pude observar que se efectuaban a veces, pero desde luego no siempre ${ }^{27}$. Y lo que es más importante, descubrí que la interpretación que del método de verificación se hacía no siempre estaba de acuerdo con el principio básico del conceptualismo, de acuerdo con el cual el Derecho positivo siempre debía ser respetado. La categorización en cuestión no estaba necesariamente

estudiar el Derecho mercantil. Fue profesor de Derecho mercantil en la Universidad de Helsinki en 1949-1961.

${ }^{25}$ Es cierto que sus resultados fueron duramente criticados por Hakulinen, pero la discusión permaneció dentro del marco de referencia conceptual. Hakulinen no criticaba el método utilizado, sino los resultados obtenidos, que en su opinión eran construcciones incorrectas. El debate entre Hakulinen y Heikonen ha sido tratado en detalle por Aulis Aarnio, Perillisen oikeusasemasta (1967) (La posición jurídica del heredero), págs. 97-113.

${ }^{26}$ Esta era la opinión de Caselius en su condición de oponente oficial de la tesis doctoral de Heikonen, Lakimies, 1937, pág. 286.

${ }^{27}$ Es posible, sin embargo, que los juristas que no se referían explícitamente a esta contradicción, llevaran a cabo mentalmente la comprobación. 
condenada a ser refutada por la existencia de una norma del Derecho escrito que chocara con la regla jurídica extraída de la categoría. Al contrario, la contradicción a veces debilitaba la posición de la norma jurídica, que entonces era considerada una norma especial sujeta a interpretación restrictiva. La disposición conforme con la construcción conceptualista podía elevarse al rango de norma principal aplicable a casos distintos de los directamente cubiertos por ella ${ }^{28}$.

Estas observaciones proporcionan una imagen interesante de la concepción de la relación entre el Derecho positivo y la doctrina general predominante en los años treinta. De acuerdo con nuestra tradición legalista, se aceptaba la importancia primaria de la legislación, pero ésta se interpretaba por medio de un marco de referencia formado por teorías basadas originariamente en las Pandectas. Esto implicaba que el status de una norma como principal o como excepción se determinaba por su corrección doctrinal. Así, con la ayuda de los principios generales la ciencia jurídica podía controlar el desarrollo del Derecho.

4.2. Un corolario de todo lo que acabo de describir es que, en los años treinta, los precedentes jugaban solamente un papel modesto en la argumentación. Los juristas no los consideraban una fuente real del Derecho, salvo cuando la solución que contenían era adoptada por la práctica jurídica, convirtiéndose de esta forma en Derecho por la vía de la costumbre jurídica.

La importancia de los precedentes, sin embargo, variaba de un autor a otro. En los Estudios de Hakulinen y Heikonen su papel era muy restringido. La monografía de Heikonen sobre el derecho de sucesiones, en dos volúmenes, no contiene virtualmente ninguna referencia a la práctica jurídica. Por otra parte, el uso de la práctica jurídica parece haber sido asimétrico, en el sentido de que se aceptaba para corroborar la opinión de los juristas, pero no para refutar los resultados conseguidos por otros medios ${ }^{29}$.

28 Inter alia Hakulinen, Perusteettoman edun palautus (1931) (Reparación del enriquecimiento injusto), págs. 140 y 296 comparadas con págs. 175, 210 y 251.

${ }^{29}$ Esta asimetría está de acuerdo con el acercamiento científico de la dogmática conceptualista. El argumento era que el precedente no tenía importancia propia desde el propio punto de vista de la justificación de soluciones porque éstas debían basarse en elementos sistemáticos internos a la ciencia jurídica. De aquí el que los precedentes no pudieran refutar un resultado. Si, por el contrario, el jurista y el tribunal llegaban a la misma conclusión independientemente del otro, el resultado era confirmado, pues la coincidencia de las dos soluciones probaba que la inferencia era correcta. 
Caselius adoptó, junto con algunos otros juristas, una actitud mas ecléctica hacia la metodología y prestó más atención a los precedentes, aunque su peso en su argumentación variaba. En general, a Caselius no parecía importarle mucho que el caso del que informaba se ajustara a su punto de vista o no. Esto muestra que los precedentes eran utilizados sobre todo como ilustraciones y no como fuente del Derecho en sentido estricto.

4.3. En los años treinta las consideraciones prácticas tenían mucha menos importancia que durante el episodio realista. En este punto Hakulinen y Heikonen mantenían visiones extremas. Hakulinen distinguía entre argumentos jurídicos y fácticos para justificar una regla jurídica. Según él, los factores prácticos pertenecían al segundo grupo y, consecuentemente, no formaban parte de la argumentación jurídica. De esta forma, podían perfectamente no ser utilizados para controlar los resultados procedentes de las construcciones conceptualistas.

En la literatura jurídica hay ciertamente casos que, aun siendo admitidamente cuestionables desde un punto de vista práctico, se aceptaba que correspondían al Derecho positivo porque se deducían de una construcción conceptualista ${ }^{30}$. Esto refleja la idea de que sólo el legislador puede hacer una excepción a una solución determinada por el sistema; al investigador, en cambio, no le está permitido hacerlo aludiendo a consideraciones prácticas. Tales argumentos sólo pueden utilizarse como último recurso, cuando ya no quedan otros argumentos.

La mayoría de los juristas adoptó una actitud más ecléctica. Caselius, Noponen, Raninen, Rekola y Sipilä, por ejemplo, no consideraban insoluble el conflicto entre el uso de consideraciones prácticas y la inferencia a partir de conceptos, sino que, por el contrario, aplicaban uno u otro método dependiendo de las circunstancias. Parece imposible extraer de sus escritos un principio general sobre en qué casos debe aplicarse una u otra técnica. En conjunto, el método constructivo ciertamente jugaba un papel considerable.

Debido a la poderosa posición de la dogmática conceptualista, las reglas jurídicas ofrecidas por los juristas como resultados de su estudio eran bastante abstractas. Las consecuencias jurídicas estaban normalmente conectadas no a hechos concretos, sino a construcciones jurídicas, especialmente a derechos subjetivos. Como el número de construcciones era muy limitado en comparación

219.

\footnotetext{
${ }^{30}$ Inter alia Heikonen, Perinnönyhtydestä II (1937) (Sobre el patrimonio hereditario), pág.
} 
con la gran variedad de situaciones de la vida diaria, el Derecho creado por los estudiosos aparecía esquemático. Cuestiones jurídicas que no parecían tener nada en común eran resueltas de acuerdo con el mismo patrón.

4.4. Sin embargo, el enfoque conceptualista no iba a permanecer en paz mucho tiempo. Al final de los años treinta se convirtió de nuevo en el objeto de la crítica. Kivimäki expresó una moderada opinión en contra de una concepción radical de la dogmática conceptualista. Pero adoptó una actitud básicamente positiva hacia el enfoque conceptualista, de la misma forma que había hecho en su artículo de quince años antes: señaló sus ventajas sistemáticas y su capacidad para percibir similitudes en fenómenos aparentemente diferentes.

A su juicio, la importancia de estas características aumentaría todavía en el futuro, debido a que la sociedad se haría cada vez más compleja y la regulación legal se expandiría, lo que exigiría un control más sistemático del Derecho. Kivimäki también destacó los méritos de la dogmática conceptualista desde el punto de vista del desarrollo de la cultura jurídica. En su opinión, este enfoque había permitido la elaboración de conjuntos enteros de nuevas normas que el Derecho escrito ni siquiera mencionaba ${ }^{31}$.

Sin embargo, Kivimäki también conocía las desventajas de la aplicación del método conceptualista. Creía que este enfoque había conducido a la petrificación de los principios jurídicos y a la transformación de la ciencia jurídica en dogmatismo. Al deducir consecuencias legales de las construcciones, los aspectos históricos y sociales de los fenómenos jurídicos no recibían suficiente atención y, de esta forma, los resultados obtenidos eran extraños a la vida real. Creía también que la razón de esto era que los puntos de vista socialmente orientados eran ya mas generales, mientras que la doctrina conceptualista se basaba en el Derecho romano, individualista, o en los sistemas jurídicos procedentes de él.

${ }^{31}$ T. M. Kivimäki, «Lainkäytön ja oikeustieteen oikeutta kehittävästä merkityksestä» («Sobre la importancia de la Administración de Justicia y de la Ciencia Jurídica desde el punto de vista del desarrollo del Derecho»), Lakimies, 1937, págs. 480 y sigs. No hay duda de que Kivimäki tenía razón en este punto. El conceptualismo finlandés merece crédito por haber desarrollado la cultura jurídica. $\mathrm{Al}$ concebir las normas individuales y casuísticas como manifestaciones de principios generales, los seguidores de esta escuela consiguieron introducir la doctrina extranjera. Esto hizo posible desarrollar el Derecho privado con independencia de la legislación, lo que siguiendo nuestras tradiciones jurídicas habría sido difícil. 
Kivimäki, sin embargo, no pensaba que el enfoque conceptualista en sí mismo estuviera acabado. Afirmaba, por el contrario, que la categorización y la inferencia deductiva eran todavía instrumentos útiles. Sólo se necesitaba un cambio para adaptar las categorías a las nuevas circunstancias sociales.

Las críticas a la dogmática conceptualista de Haataja y de Af Hällström eran más severas y fundamentales. Ninguno de ellos publicó sus opiniones de una forma global y sistemática. Sus observaciones críticas pueden encontrarse en revistas relacionadas con las aplicaciones del método constructivo.

Haataja puede ser considerado un seguidor de la jurisprudencia histórica de intereses. Sostenía que el Derecho válido es el resultado orgánico de la evolución histórica. Partiendo de aquí, criticaba la influencia alemana que las categorías conceptualistas transmitían a la interpretación del Derecho positivo. En su opinión, los modelos jurídicos procedentes de la tradición nórdica no podían ponerse en las categorías derivadas de un Derecho extranjero sin, en cierta medida, afectar negativamente el Derecho finlandés.

Además, afirmaba que en la dogmática finlandesa la deducción no es un método apropiado y debe ser reemplazada por la inducción. Los problemas jurídicos concretos no pueden resolverse extrayendo conclusiones de categorías, sino estudiando nuestra propia tradición y nuestro Derecho positivo con la ayuda de la interpretación histórica. Solamente después de que los problemas concretos hayan sido resueltos de esta manera será posible elaborar una construcción sistemática que cubra las necesidades de sistematización realizando una generalización inductiva sobre estos concretos resultados.

Erik af Hällström ponía menos énfasis en la tradición. Su principal idea era la exigencia de que las reglas jurídicas debían servir a objetivos sociales de una forma óptima. Pero sus conclusiones prácticas eran similares a las de Haataja.

Afirmaba que el método de deducir nuevas reglas jurídicas a partir de construcciones debía rechazarse incluso cuando la construcción había sido inducida a partir del Derecho finlandés. En su opinión, las construcciones eran importantes sólo desde el ángulo de la sistematización y no podían utilizarse para justificar puntos de vista en la dogmática. La justificación debía fundarse en el Derecho escrito y sobre todo en consideraciones prácticas. Para manejar estas últimas era necesario un conocimiento completo de los aspectos prácticos del sistema jurídico.

Entre los críticos del enfoque conceptualista también estaba Otto Brusiin. En su libro sobre la discreción judicial en los supuestos 
de lagunas jurídicas, Brusiin acentuaba el significado de los argumentos prácticos y el conocimiento fáctico de la sociedad para la elaboración de soluciones jurídicas. Él, como los Realistas Escandinavos, consideraba el ordenamiento un instrumento de ingeniería social y rechazaba el «método de justicia», que recurría a la equidad para buscar soluciones en vez de aplicar el razonamiento de medios y fines ${ }^{32}$. En sus escritos hay también un razonamiento que, en cierta medida, recuerda el argumento ontológico utilizado por la Escuela de Uppsala contra la dogmática conceptualista ${ }^{33}$. En general, este argumento no fue muy apreciado en Finlandia.

\section{El período de cambio}

5.1. La influencia escandinava sobre la investigación en Derecho civil finlandesa aumentó considerablemente durante los años cuarenta. La línea de pensamiento que antes podía sólo encontrarse en los escritos de unos pocos pioneros consiguió penetrar mayoritariamente y fue incorporada a las actividades de investigación. El interés metodológico giró hacia la ciencia jurídica instrumental, que se centraba en la ingeniería social y en las consideraciones prácticas.

El cambio, sin duda, fue en parte causado por factores externos a la ciencia jurídica. El más evidente de estos elementos fue el colapso de Alemania al final de la segunda guerra mundial, lo que dio fin a su influencia cultural. Sin embargo, ya antes de esto, cuando el resultado de la guerra producía inquietud y miedo en Finlandia, hubo intentos de conseguir apoyo de Escandinavia y de su herencia cultural en lugar de Alemania. La orientación hacia Escandinavia era una alternativa natural, especialmente para los intelectuales que hablaban sueco. Esto puede observarse en las revistas jurídicas de ese tiempo. La FJFT, una publicación en sueco, tenía una marcada influencia escandinava; destacaba las relaciones con Escandinavia y las raíces escandinavas del sistema jurídico. En cambio, ninguna de

${ }^{32}$ Brusiin, Tuomarin harkinta normin puuttuessa (1938) (La discreción judicial en la ausencia de norma), págs. 165, 190-192 y 204-229.

${ }^{33}$ Por el argumento ontológico entiendo la visión de que las construcciones jurídicas son entidades metafisicas no existentes y de que la interpretación a través de la construcción implica inferir consecuencias legales de elementos no existentes. 
estas cosas podía encontrarse en la revista Lakimies, publicación en finés.

Los argumentos científicos utilizados para justificar el cambio eran ya conocidos, en gran medida, por los escritos teóricos de finales de los años treinta. En las investigaciones concretas los factores históricos señalados por Haataja no fueron, sin embargo, tenidos en cuenta y el análisis se centró en la racionalidad de los objetivos de las reglas jurídicas. No fue la falta de historicidad del método constructivo lo que se sometió a crítica, sino su carácter no práctico. De acuerdo con sus críticos, la sistemática de las Pandectas unió, por una parte, en una misma categoría fenómenos jurídicos que no tenían una conexión real entre sí y, por otra, separó materias que funcionalmente se encontraban unidas ${ }^{34}$.

La crítica al marco de referencia conceptualista recibió nuevos estímulos cuando la filosofía empírica de la ciencia, desarrollada por el positivismo lógico, empezó a tener efecto en la dogmática. Ahora se rechazaba el método deductivo por no ser empírico ${ }^{35}$. Esta línea de pensamiento acusaba al enfoque conceptualista de desatender el material legal, que formaba «la base natural de la dogmática», y de utilizar doctrinas generales en su lugar. Estas se consideraban un tipo de prejuicios que impedían a los juristas analizar el contenido del Derecho escrito con suficiente precisión ${ }^{36}$.

Consecuentemente, muchos iusprivatistas empezaron a eliminar la doctrina general y las consecuencias inferidas de ella. El precursor de esta escuela de pensamiento fue Af Hällström en su estudio sobre la venta condicional y fue seguido por muchos juristas de habla sueca ${ }^{37}$. En ese momento, la división de opinión

${ }^{34}$ Eg af Hällström, Verkan av ägareförbehall pa rättsförhallandet mellan säljaren och köparen (1942), pág. 97.

${ }^{35}$ Eg af Hällström, op. cit., págs. 13-14, Taxell, Aktiebolagstyrelsens kompetens att rättshandla (1946), págs. 6-10, Ek, Bidrag till läran om utomeobligatoriskt skadestansansvar vid rättsenling farlig verksamhet enligt Finlands gällande civilrätt (1943), págs. 3-7, y Godenhielm, Nagra ord om juridiken som vetenskap, Defensor Legis, 1948, págs. 12-17.

${ }^{36}$ Es bien conocido que la escuela de Uppsala extrajo de sus puntos de vista empiristas la conclusión de que las construcciones jurídicas son conceptos metafísicos que no tienen contrapartida en la realidad. Aunque el acercamiento empirista se hizo mayoritario, este postulado no obtuvo apoyo adicional. Los civilistas no quisieron aceptar un reto que les habría obligado a elucidar los fundamentos de su ciencia.

${ }^{37}$ Af Hällström fue profesor (de habla sueca) de Derecho civil en la Universidad de Helsinki durante 1940-1951. 
sobre la metodología del Derecho civil coincidía en gran medida con la separación entre las dos comunidades lingüísticas.

La nueva tendencia realista proscribía la inferencia de consecuencias jurídicas de principios y categorías que emanaran de la jurisprudencia de conceptos. Como ejemplos podemos mencionar la distinción entre el derecho de propiedad y el derecho de obligaciones, el principio según el cual los derechos subjetivos son indivisibles y presuposición inherente de que se transmiten como entidades indivisas en un momento dado. Al mismo grupo pertenecían principios muy importantes relativos al derecho de gravamen, en el principio de su naturaleza accesoria, así como principios relativos al derecho matrimonial, al derecho de sucesiones y al de sociedades.

Al proscribir estas construcciones y los dogmas a ellas unidos, la nueva escuela de pensamiento tenía de hecho semejanzas con las opiniones de Lundstedt rechazando totalmente los conceptos. Sin embargo, las teorías de Lundstedt no fueron directamente utilizadas como modelo -todavía se consideraba un jurista cuyas ideas no debían ser tomadas en serio-, pero el patrón adoptado provenía de la investigación sueca sobre dogmática jurídica concreta ${ }^{38}$.

5.2. La disminución de la importancia de la doctrina general influyó tanto en la elección de materias de investigación, como en la argumentación jurídica. La categorización de los fenómenos ya no se consideraba un problema jurídico relevante. El conocimiento jurídico relevante no era sobre categorías, sino el conocimiento de las relaciones entre hechos y efectos jurídicos.

Como ejemplo, podemos de nuevo referirnos al estudio de Af Hällström sobre la venta condicional. En su tratado el desarrollo de la relación jurídica entre el comprador y el vendedor es entendido como un proceso a lo largo del cual el derecho de propiedad es gradualmente transferido al comprador. El propósito de Af Hällström era establecer qué consecuencias jurídicas se asocian a los diferentes estadios del proceso, como la perfección

${ }^{38}$ T. S. Kuhn ha señalado las semejanzas entre el trabajo científico y el manual. Según él, los investigadores no aprenden normalmente su oficio estudiando abstractas reglas metodológicas. Más bien reciben su aprendizaje llevando a cabo labores de investigación concreta, de la misma forma que el aprendiz aprende de su maestro. En otras palabras, el investigador utiliza una investigación concreta de su campo como modelo e intenta aplicar algunas de sus características de forma análoga a su propio trabajo. Kuhn ha desarrollado esta teoría dentro del marco de referencia de las ciencias naturales, pero al menos en este caso también puede referirse a la dogmática. Véase Kuhn, The Structure of Scientific Revolutions (1970), pág. 44. 
del contrato, la entrega de los bienes al comprador, el vencimiento de la deuda dineraria del comprador, y el pago del precio. Los efectos jurídicos constituyen el factor desconocido en este esquema.

Taxell procedió de la misma forma en su libro sobre la entrega en prenda de bonos. No investigó la naturaleza del derecho de gravamen creado por la prenda de los bonos, sino que intentó elucidar las consecuencias jurídicas de actos típicos tales como la perfección del contrato de prenda, el traspaso de la posesión del bono como prenda y el vencimiento de la deuda. Las consecuencias jurídicas eran, también en este caso, el factor desconocido.

5.3. Examinemos ahora la argumentación. Como se rechazaba la relevancia de la doctrina general desde el punto de vista de la argumentación; había un vacío que debía ser cubierto. Para ello se utilizaban las consideraciones prácticas. Los civilistas de habla sueca acentuaron la importancia de estos argumentos. Afirmaban que las consideraciones prácticas debían tener pleno reconocimiento como fuente del Derecho y que no debían meramente servir como un último recurso de permitir al juez encontrar una solución a un caso particular sobre el que el Derecho guardaba silencio.

Las exigencias más radicales fueron planteadas por Af Hällström. Él reclamaba que las consideraciones prácticas debían jugar una parte decisiva siempre que el Derecho no lo impidiera directamente. En su opinión, estas consideraciones podían incluso, bajo ciertas condiciones, suplantar al Derecho positivo: «Una norma jurídica que ha sido promulgada en oposición a las circunstancias económicas y sociales debe ser abandonada, aunque siga siendo derecho válido, y reemplazado por una regla cuyo contenido se determina por medio de la otra fuente del Derecho que he mencionado» ${ }^{39}$.

Gunnar Palmgren sostenía el mismo punto de vista. Argumentaba que el legislador no puede siempre seguir los pasos de los rápidos cambios sociales. Por tanto, la ciencia jurídica debía adoptar un nuevo papel y, si es necesario, crear derecho en lugar de agarrarse a una legislación obsoleta ${ }^{40}$.

Los defensores del método realista intentaron cambiar la naturaleza de las reglas elaboradas por la investigación de la dogmática. Estas debían ser prácticas y apropiadas y debían promover el progreso social.

${ }^{39}$ Af Hällström, op. cit., pág. 19.

${ }^{40}$ Gunnar Palmgren, Nagra synpunkter pa rättsvetenskapens arbetsuppgifter, Nya Argus, 1940, pág. 178. 
Erik af Hällström describió la técnica que había aplicado en su estudio sobre la venta condicional como un intento de valorar un procedimiento desarrollado en la vida del comercio a la luz de sus efectos sociales. Sostenía que este procedimiento debía ser apoyado por la dogmática si se probaba que promovía el desarrollo social y económico, si estimulaba la producción y el comercio o cumplía fundadas necesidades del crédito. Si no se conseguían estos fines, no debía recibir apoyo y el procedimiento dejaría de existir ${ }^{41}$. Ideas similares sobre la relación entre la vida comercial y la dogmática pueden encontrarse en los escritos de algunos otros juristas ${ }^{42}$.

Si utilizamos estos breves ejemplos como base para una caracterización general del acercamiento científico adoptado por estos investigadores, podemos decir que eran seguidores del instrumentalismo pragmático en más o menos el sentido en que es utilizado por Summers en su monografía sobre el Realismo Americano ${ }^{43}$. De acuerdo con este marco de referencia, la dogmática es un instrumento para alcanzar determinados objetivos sociales. Por medio de la utilización de consideraciones prácticas y del método de interpretación teleológica para resolver cuestiones jurídicas, los valores en cuestión pueden ser realizados en beneficio de la vida social y económica.

En la investigación llevada a cabo en los años cuarenta el requisito de que las consideraciones prácticas deben ser tenidas en cuenta no era una exigencia meramente teórica, sino que fue en gran medida aplicado en estudios prácticos. Las materias elegidas eran adecuadas para la aplicación de argumentos prácticos. La investigación de Af Hällström sobre la venta condicional le permitió analizar los aspectos dinámicos de los derechos, que habían causado grandes problemas a los juristas del punto de partida tradicional. Como el derecho legislado que regulaba esta materia era escaso, pudo referirse ampliamente a consideraciones prácticas y criticar la vieja doctrina.

Ek eligió un tema relacionado con la compensación por daños que le ofrecía más o menos las mismas ventajas. La Ley de Sociedades era vieja y estaba llena de lagunas, lo que proporcionó a Taxell y Olsson la oportunidad de probar su capacidad

${ }^{41}$ Af Hällström, op. cit., págs. 13-14.

${ }^{42}$ Inter alia Taxell, Aktiebolagstyrelsens kompetens att rättshandla (1946), págs. 6-7.

${ }^{43}$ Robert S. Summers, Instrumentalism and American legal theory (1982), págs. 60-61 y 146-147. No hay relación causal entre el Realismo Americano y la dogmática finlandesa. Esta surgió de los modelos escandinavos. 
elaborando argumentos basados en consideraciones prácticas ${ }^{44}$. El mismo modelo puede encontrarse en artículos menores.

Había una variedad de objetivos que servían como consideraciones prácticas. Algunos de ellos eran superiores en la jerarquía de medios y fines, como por ejemplo «los intereses del comercio», «la seguridad del tráfico» y «los intereses de la vida comercial». Ejemplos más concretos eran «la prevención de daños», «el asegurar la compensación», «el conservar la propiedad de la compañía» y diferentes fines procedimentales tales como «la sencillez y bajo precio en la venta de una prenda».

En la literatura jurídica no se proporcionaba justificación de los objetivos seleccionados. Esto era posible porque todos los juristas parecían ser unánimes en esta materia. Cuando los objetivos entraban en conflicto, el problema se solucionaba ponderando los intereses en juego. En este proceso se daba generalmente preferencia a razones relacionadas con la promoción del comercio e intereses semejantes. Promover el comercio era sin duda el objetivo central de la investigación de Derecho privado de aquel tiempo. Los juicios de valor subyacentes en la argumentación eran puramente burgueses en el sentido original de la palabra. Argumentos como la igualdad social o la protección de la parte más débil no eran tenidos en cuenta.

5.4. Los juristas que destacaban la importancia de las consideraciones prácticas también ponían más énfasis en los precedentes. En su opinión, la dogmática finlandesa debía dejar de descuidar los precedentes y empezar a prestarles seria atención, como ya se había hecho en otros países nórdicos.

Sin embargo, no exigían que los precedentes tuvieran el status de fuente autorizada del Derecho. Su pretensión de que los juristas conocieran los precedentes se basaba en la idea de que la dogmática debe ser práctica y cercana a la vida real. Sostenían que los precedentes y otros casos judiciales contenían información sobre cuestiones prácticas que ofrecía preguntas relevantes y razonables respuestas.

Si comparamos la importancia dada a los precedentes y a las consideraciones prácticas, estas últimas parecían prevalecer. Sin duda, en los años cuarenta no existía un «positivismo judicial» que asimilara las decisiones del Tribunal Supremo al derecho válido. Los juristas no querían someter la ciencia a la práctica

${ }^{44}$ Taxell, op. cit., Olsson, Aktieförvärvares rätt i förhallande till bolaget (1949). 
jurídica. Al contrario, pensaban que las consideraciones prácticas podían utilizarse para someter los precedentes a la crítica debida.

5.5. Cuando examinamos las consecuencias de la aplicación del nuevo método realista, podemos observar que en el análisis de normas J. la importancia de los derechos subjetivos había disminuido considerablemente. Los efectos jurídicos ya no se conectaban con derechos subjetivos ni con ninguna otra categoría, sino con hechos jurídicos de una clase distinta, i.e. más casuísticos y más comunes.

De esta forma, se satisfizo la exigencia del Realismo Escandinavo de que las consecuencias jurídicas se conectaran a hechos jurídicos reales y prácticos y no a construcciones metafísicas. Aunque este cambio coincide con el enfoque realista, parece haberse originado a partir de factores prácticos, más que filosóficos. La problemática ontología de los derechos no se utilizó como justificación del nuevo método.

Dos tendencias principales pueden distinguirse en los escritos en que se aplicó el nuevo método. La primera, encabezada por Taxell, fue una reacción contra la rigidez de la dogmática conceptualista. El ideal de esta tendencia era encontrar una solución a la medida para cada caso particular, de forma que se pudieran tener en cuenta sus características individuales. Esto implicaba que el número de hechos jurídicamente relevantes aumentaba considerablemente. Como principio, todos los rasgos casuísticos del caso se transformaban en hechos que, en mayor o menor medida, influían en la decisión.

Establecer las soluciones casuísticas como ideal causa problemas a la dogmática. Esta no puede centrarse en reflexiones sobre la relevancia jurídica de características exclusivas de casos particulares. Para obtener una relevancia más general debe centrarse en tipos de casos, en categorías en gran medida privadas de elementos individuales.

Taxell era consciente de esta dificultad y para resolverla afirmó que la dogmática no debe crear reglas que impongan demasiadas limitaciones a los juristas que explican el Derecho. Los resultados de la investigación deben formularse como cláusulas generales flexibles, que dejen al juez libertad para considerar las características individuales del caso. Taxell observó este postulado en su propia investigación; posteriormente, fue también seguido por otros.

Aparentemente, las cláusulas generales fueron introducidas en el Derecho privado finlandés principalmente por la dogmática. Las cláusulas generales incluidas en el Derecho escrito constituían 
sólo una pequeña fracción de las presentadas por la comunidad de juristas como resultados de la dogmática.

Af Hällström utilizó las consideraciones prácticas de una forma enteramente diferente. Aunque los factores prácticos también le llevaron a ampliar sus análisis, las reglas que él elaboró eran precisas y dejaban sólo el grado de discreción usual a los juristas que las aplicaran. Su objetivo parecía ser la formulación de reglas claras basadas en consideraciones prácticas.

En cierta medida, probablemente Af Hällström todavía valoraba la rigidez de las normas. Al determinar el contenido de una norma, argumentaba, el acento no debe ponerse sólo en la cuestión de si la norma es flexible y hace posible una solución óptima en un caso concreto. La función de guía de la regla desde el punto de vista de la práctica jurídica también debe tenerse en cuenta, i.e. su capacidad para evitar controversias. Esto exige que la norma tenga un cierto grado de rigidez.

Para Af Hällström, esta rigidez no debe imponerse siguiendo los principios de las Pandectas, sino teniendo en cuenta las consideraciones prácticas. En este sentido, así como en su actitud negativa hacia los argumentos de equidad, las opiniones de Af Hällström no diferían mucho de las de, por ejemplo, Lundstedt.

5.6. El éxito de la dogmática jurídica basada en la ingeniería social no produjo una desaparición rápida de la escuela de pensamiento conceptualista. Los juristas que antes se habían adherido a procedimientos constructivos continuaron trabajando de la misma forma. Los más importantes entre ellos continuaron siendo Hakulinen y Heikonen. En sus numerosas obras los problemas se resolvían por medio de la categorización y de la inferencia a partir de categorías. La severa crítica a que la deducción de conceptos había sido sometida no pareció influirles.

Sin embargo, la fuerza de la tradición conceptualista se debilitaba por falta de seguidores. Hannikainen era una excepción significativa. $\mathrm{Su}$ libro Pidätysoikeuden rakenteesta (Sobre la estructura del derecho de retención) se basaba en un marco de referencia fuertemente constructivo.

Los seguidores del enfoque conceptualista no pudieron ya conseguir un debate a fondo con los partidarios del nuevo método. Las suspicacias que el nuevo método producía se manifestaron como comentarios en recensiones de libros y otros escritos menores. La crítica se dirigía fundamentalmente contra dos características del nuevo método; su excesivo interés por las consideraciones prácticas y el hecho de que eliminaba la conexión entre la sistemática y la casuística optando parcialmente por la segunda. 
Quizá el comentario más interesante sobre el cambio culpaba al método realista del deterioro de la cultura jurídica en los países nórdicos. Permítanme citar a Caselius: «De la misma forma que en el negocio de la construcción el conocimiento práctico del maestro constructor se considera superior al del arquitecto, se dice a veces que el conocimiento de un miembro lego de un juzgado es más valioso que un libro de Derecho. Se admiran ahora los jueces del pasado que no mezclaban la teoría con su lógica, sino que basaban sus decisiones en su conciencia y en la Ley de 1734, la mejor de todas las leyes, si es que necesitaban algún derecho escrito. La misma línea de pensamiento subyace en la tendencia ahora de moda de rechazar todos los conceptos y construcciones y de resolver todos los problemas refiriéndose a las «consideraciones prácticas» (...) De esta forma, la evolución de siglos de la ciencia jurídica es despreciada y, con alivio para el científico, no necesita ser estudiada. Todos los problemas que surgen son fácilmente resueltos en la forma exigida por los «factores económicos» o el «punto de vista práctico» que casualmente tengan relación con el problema».

Hakulinen expresó la misma preocupación, en términos menos perentorios, en un artículo en que destacaba la importancia del Derecho romano y del Digesto como fuentes de una cultura jurídica europea fundamental ${ }^{45}$. Afirmaba que rechazando estas fuentes el Derecho civil rompía con sus raíces europeas.

\section{El período de consolidación}

6.1. La siguiente década, los años cincuenta, no aportó básicamente nuevos elementos a la discusión sobre la argumentación jurídica. El debate sobre la importancia proporcional de las diferentes fuentes del Derecho, que se había desarrollado en un nivel general, palideció. Los seguidores del nuevo método no creían que mereciera la pena continuarlo, pues pensaban que la sustitución ya había tenido lugar. En efecto, el nuevo método había tenido un éxito considerable, ya que la nueva generación de juristas de habla finesa, que habían empezado a publicar en los años cincuenta, adoptó el método realista y sus postulados

${ }^{45}$ Caselius, «Memorándum del Oponente Oficial de Tesis Doctoral de Hannikainen», Lakimies, 1948, pág. 477; Hakulinen, «Latinankieli ja lainoppi» («Latín y dogmática jurídica»), Lakimies, 1949, págs. 341 y sigs. Entre los otros críticos del nuevo método debe mencionarse a B. C. Carlson, inter alia Reella överväganden, Defensor Legis, 1944, págs. 191 y sigs., y 320 y sigs. 
epistemológicos. Sólo unos pocos juristas de la generación anterior permanecieron fieles al enfoque conceptualista.

De acuerdo con los principios epistemológicos de la nueva escuela de pensamiento, el conocimiento jurídico es un conocimiento sobre normas, en otras palabras, sobre las relaciones entre hechos y consecuencias jurídicas. Este punto de vista se ha confirmado por los resultados de la discusión que sobre los derechos subjetivos había tenido lugar en Escandinavia. Según éstos, los derechos subjetivos no existían como entidades independientes, sino que no eran otra cosa que hechos o efectos jurídicos, o en algunos casos debían ser considerados términos sin referencia que permitían la combinación de varias relaciones entre hechos y consecuencias con el propósito de presentación técnica ${ }^{46}$.

Consecuentemente, el conocimiento del Derecho privado no podía ocuparse de los derechos subjetivos y de su naturaleza. Las reflexiones sobre la esencia de estos derechos sólo conducían a un estudio esquemático e indirecto de los problemas jurídicos reales, mientras que el nuevo enfoque quería atacarlos directamente. Las materias que en el modo de pensamiento precedente tenían conexión unas con otras se rompieron en un gran número de cuestiones menores que se resolvían independientemente unas de otras. Se decía que «ahora es el tiempo de hacer análisis» ${ }^{47}$.

La dicotomía hechos-consecuencias jurídicas también determinó la formulación de problemas de investigación ${ }^{48}$. Se elegían tanto las consecuencias como los hechos jurídicos como factor desconocido. Normalmente, el acento se ponía en los hechos jurídicos o en parte de ellos como requisitos previos para los efectos

${ }^{46}$ La discusión sobre los derechos subjetivos fue uno de los logros más notables del Realismo Escandinavo. Surgió de los intentos de desarrollar o criticar la afirmación de Hägerström de que los derechos subjetivos no existen y de que cualquier presunción que implique su existencia es metafísica. De los escritos significativos sobre esta materia debemos mencionar: Hedenius, Om rätt och moral (1941), Olivecrona, Omlagen och staten (1940), Ekelöf, «Juridisk slutledning och terminologi», TfR, 1945, págs. 213 y sigs.; Strahl, «Till fragan om rättighetsbegreppet», TfR, 1946, págs. 204 y sigs. y TfR, 1947, págs. 481 y sigs.; Ross, Tû-Tû, Festkrift till professor dr. juris Henry Ussing (1951), Wedberg, «Some problems in the logical analysis of legal science», Theoria, 1951, págs. 246 y sigs. Un excelente examen de la discusión ha sido realizado por Sundby, «Legal right in Scandinavian analysis», Natural Law Forum, 1968, págs. 72 y sigs.

${ }^{47}$ Inter alia Muukkonen, Muotosäännökset (1958), pág. 133, yZitting, «Omistajan oikeuksista ja velvollisuuksista» («Sobre los derechos y obligaciones del propietario»), Lakimies, 1952, págs. 530-531.

${ }^{48}$ Esta distinción fue explícitamente utilizada por eg Zitting, Ylöstalo, Olsson, Lahtinen, Vuorio, Muukkonen, von Bonsdorff ja Godenhielm. 
jurídicos. Esto es algo natural, pues en el Derecho civil los hechos son relativamente complejos en comparación con las consecuencias.

En el tratamiento de estas cuestiones las consideraciones prácticas jugaban un importante papel, quizá incluso clave. El nuevo método implicaba que la dogmática jurídica era una argumentación basada en consideraciones prácticas dentro del marco más amplio constituido por el Derecho positivo y por los precedentes. Una parte esencial de la habilidad del investigador consistía en adaptar el marco sin forzarlo.

Cuando se aplicaban estas ideas a la investigación concreta el rechazo de las doctrinas generales continuaba. La primera tarea del jurista al examinar una cuestión nueva era atacar los dogmas y principios que antes se consideraban relevantes desde el punto de vista de la evaluación del problema. Después de esto, quedaba libre el camino para la aplicación de los argumentos referidos a objetivos.

Los fines que se utilizaban eran más o menos los mismos que en los años cuarenta. Ejemplos de objetivos generales frecuentemente mencionados en la literatura son: «la promoción de la producción y el comercio», «aumentar la flexibilidad y carácter práctico», «ahorrar tiempo y trabajo», «incentivar la libre empresa»y «la libertad, seguridad y continuidad del comercio».

En otras palabras, el propósito de la regulación era actuar como un lubricante que permitiera la eliminación de fricciones en las ruedas de la economía... Algunos objetivos menores que podían utilizarse para apoyar los fines generales eran, entre otros, una actividad de recompensa y la protección de la confianza. En la relación de intercambio se consideraba que las partes eficientes y de buena fe merecían una protección especial.

6.2. De acuerdo con la nueva escuela de pensamiento, la aplicación de la idea de que el Derecho es una forma de ingeniería social conduce a una argumentación de conocimiento práctico de la sociedad. Empezando por los objetivos generales, la jerarquía de fines y medios debía elucidarse procediendo de arriba a abajo. Este procedimiento debía continuarse hasta que el nivel de análisis conseguido permitiera el uso del objetivo (o del medio) como un elemento operacional en una regla jurídica. Una ejecución completa de esta labor exigía recurrir a las ciencias sociales.

La realización de estas ideas en la dogmática jurídica normalmente no alcanzó los objetivos exactos fijados. Generalmente, los juristas no recorrían toda la jerarquía de medios y fines, sino que pasaban directamente de los objetivos generales a la 
selección de hechos operacionales. Algunas veces se seguía el procedimiento contrario, lo que significaba que se determinaban los hechos y circunstancias relevantes en consideración a concretos objetivos menores que no eran comparados con los fines generales.

Sería equivocado, sin embargo, decir que no hubo intentos serios de llevar a cabo un programa de investigación del Derecho como ingeniería social. Algunos estudios tratan detalladamente las relaciones causales incluidas en la jerarquía de medios y fines ${ }^{49}$. Por otra parte, el nuevo estilo de argumentación resulta muy favorablemente valorado si trasladamos nuestro punto de vista de los exigentes objetivos fijados a cómo la dogmática jurídica se realizaba antes.

6.3. Además de la doctrina general, la posición del Derecho escrito también experimentó cambios. Su importancia en la argumentación se relativizó -o al menos su relatividad fue admitida más abiertamente. Si una norma y una consideración práctica llevaban a soluciones diferentes, la primera debía prevalecer, de acuerdo con el nuevo enfoque, sólo si no era ambigua. Si dejaba espacio a la interpretación, la elección entre las alternativas debía basarse en las consecuencias de estas distintas opciones.

Esto ofrecía un amplio campo de acción a las consideraciones prácticas, pues el hecho de que las normas estaban abiertas a diversas interpretaciones se consideraba cada vez más una característica normal. Aunque los resultados de la filosofía analítica del lenguaje no habían sido todavía utilizados ampliamente en la dogmática de aquel tiempo, las nociones de «vaguedad»y «ambigüedad» ya eran, en cierta medida, familiares.

Estas características del lenguaje proporcionaban apoyo al nuevo método de interpretación que otorgaba mucha menos importancia a la literalidad de las normas. En lugar de centrarse en la letra se utilizaba el método teleológico de interpretación, que derivaba el contenido de la norma de su objetivo. Esta técnica había sido, sin duda, utilizada antes, pero ahora se convirtió claramente en parte normal de la dogmática ${ }^{50}$.

${ }^{49}$ Así, eg Olsson, Om köpares borgesärsskyddvid köp av lös egendom (1954).

${ }^{50}$ En el Realismo Escandinavo el método teleológico de interpretación fue desarrollado especialmente por Ekelöf. Véase inter alia Teleological construction of statutes, Sc. St. L., 1958, págs. 75 y sigs. Los artículos de Ekelöf sobre la materia eran conocidos en Finlandia, pero es difícil establecer con precisión qué influencia tuvieron sobre la dogmática civil. 
La prevalencia del enfoque de la interpretación teleológica no fue el único factor que cambió el papel del Derecho escrito como fuente del Derecho. Otro elemento fue que la relevancia de las normas positivas en los llamados casos difíciles fue rechazada. Si el Derecho positivo sólo ofrecía un escaso e incierto apoyo a una solución dada, la nueva escuela de pensamiento exigía que las consideraciones prácticas se usaran directamente. Se consideraban un procedimiento poco fiable el recurso a la analogía, por referirse a una norma que estaba lejos del fenómeno en cuestión; este método era denominado sintético y generalizante $^{51}$. Era hora de hacer análisis y soluciones in casu.

6.4. Sería una visión estrecha entender la evolución que tuvo lugar en los años cincuenta solamente como un paso más en la dirección de acabar con un marco de referencia sistemático. Hubo también juristas que, aunque compartían la actitud crítica escandinava a la Begriffsjurisprudenz, se inclinaban sin embargo por tratar los problemas jurídicos desde el punto de vista del sistema jurídico.

Entre estos juristas debemos hacer especial mención a Zittino. Él estaba de acuerdo con el análisis estructural del sistema jurídico planteado por el Realismo Escandinavo, por ejemplo, en la descomposición de los derechos subjetivos en relaciones entre hechos y consecuencias jurídicos. Sin embargo, a diferencia de los «realistas pragmáticos» mencionados más arriba, él no ampliaba las fuentes del Derecho introduciendo masivamente consideraciones prácticas, ni le entusiasmaba el método de resolver los problemas jurídicos in casu.

Estaba, por el contrario, muy interesado en la estructura interna del sistema jurídico. Su objetivo último parecía ser la elaboración de un sistema que reflejara mejor la estructura oculta del Derecho positivo que el enfoque conceptualista y que hiciera de nuevo posible derivar consecuencias jurídicas del sistema. Consecuentemente, creía que la fase durante la que la deficiencia del sistema conceptualista hizo imposible extraer consecuencias fiables era sólo un estadio temporal de desarrollo.

Puede decirse que Zitting, en cierta medida, compartía el punto de vista del enfoque conceptualista en lo que se refiere a la importancia de las estructuras sistemáticas de la dogmática jurídica, pero no estaba de acuerdo con el contenido del sistema. Su sistema se basaba en el Realismo Jurídico Escandinavo -en

${ }^{51}$ Más tarde este enfoque fue justificado en detalle por Makkonen en su trabajo «Zur Problematik der juridischen Entscheidung. Eine strukturanalytische Studie» (1965), esp. págs. 195-206. 
particular en la investigación de Alf Ross ${ }^{52}$. Zitting sustituyó el sistema de las Pandectas por otro más acorde con la tradición escandinava.

Como el sistema basado en las Pandectas, el esquema de Zitting era directamente aplicable a cuestiones jurídicas concretas. Esto es debido al hecho de que proporcionaba criterios nuevos para evaluar las similitudes y diferencias entre los fenómenos jurídicos. Fenómenos que bajo el viejo sistema no tenían conexión entre sí parecían ahora tener la misma estructura y viceversa.

Este método ofrecía nuevos argumentos para aplicar las normas jurídicas análogamente o para rechazar la inferencia por analogía. Al principio Zitting se centró en rechazar las analogías establecidas por el viejo sistema. Sin embargo, a diferencia de los realistas pragmáticos, no eliminó la inferencia por analogía como método jurídico, sino que confió en el poder de los argumentos sistemáticos y los aplicó en muchas conexiones diferentes.

Puede decirse que Zitting añadió nuevos elementos a la herencia del Realismo Escandinavo y también que a través de él esta escuela de pensamiento se dividió en dos tendencias en Finlandia. Una era el realismo pragmático, un enfoque de investigación que destacaba la importancia de la equidad y de la diversidad de la vida real, confiando en soluciones in casu y seleccionando libremente argumentos para justificar sus resultados. Este método sería después muy utilizado en las investigaciones sobre Derecho contractual y mercantil.

La otra tendencia era el «realismo analítico $0^{53} »$, que intentaba desarrollar el sistema jurídico con la ayuda de los resultados obtenidos por el Realismo Jurídico Escandinavo y que trataba los problemas jurídicos concretos utilizando el sistema mejorado.

${ }^{52}$ El principal trabajo de Zitting es su libro sobre la transmisión del Derecho de propiedad en los bienes inmuebles, Omistajanvaihdoksesta (1951). Ha desarrollado las mismas ideas en varios libros y artículos. Véase inter alia, An attempt to analyse the owner's legal position, Sc. St. L., 1959, págs. 227 y sigs. Sobre las opiniones de Alf Ross que constituyen la base del trabajo de Zitting, véase Virkelighed og Gyldighed i Retslaeren (1934), págs. 182-321, Ejendomsret og Ejendomsovergang med saerlingt Henblik paa dansk Retspraksis (1935) passim, y Towards a realistic jurisprudence (1946), págs. 175-299.

${ }^{53}$ La línea de pensamiento elaborada por Zitting ha sido llamada con frecuencia realismo analítico. Esta expresión es engañosa en el sentido de que el uso del análisis no es una de sus características. También los realistas pragmáticos eran analíticos, pues trataban de desmenuzar los problemas en cuestiones pequeñas para después examinarlas separadamente. Zitting difería de ellos en su enfoque sistemático, i.e. en su intento de construir un sistema partiendo de las soluciones obtenidas en cuestiones subordinadas. 
Estas ideas han sido después llevadas a cabo en la investigación sobre el derecho de propiedad («Sachenrecht»), en que el sistema de Zitting formaba el marco del programa de investigación.

Si examinamos en un mayor nivel de abstracción la dualidad de la tradición descrita, podemos ver que, a pesar de los cambios radicales que sufrió la dogmática jurídica, el mismo dilema al que me referí al principio de este artículo sobrevivió. Esta dualidad refleja el conflicto entre, por una parte, un punto de vista según el cual la dogmática debe ser un instrumento para realizar unos objetivos fijados, $y$, por otra, la idea de que los resultados de la dogmática deben deducirse de principios doctrinales. En otras palabras, la cuestión es si la dogmática debe observar el método de la ética utilitarista o de una ética deontológica.

En la teoría del Derecho la discusión sobre la argumentación jurídica ha girado hacia problemas más o menos conectados con éstos, especialmente después de las importantes contribuciones hechas por Dworkin. Hay, sin embargo, un largo camino por recorrer desde la teoría jurídica hasta las aplicaciones concretas en la dogmática -como muestra el ejemplo del Realismo Escandinavo-. Es más fácil proponer cambios en la argumentación que realizarlos en concretas investigaciones. De esta forma, es una pregunta abierta saber qué consecuencias tendrá esta discusión en el futuro.

(Trad. Jaime Alonso Gallo) 